\title{
DOCTRINA
}

\section{El acuerdo reparatorio frente a una teoría moral republicana: Apuntes desde el proceso penal chileno}

\author{
The reparatory agreement against a republican moral theory \\ in the chilean criminal process
}

\author{
Jonatan Valenzuela (iD \\ Universidad de Chile
}

\begin{abstract}
RESUMEN Este artículo se enfoca en definir, asumiendo ciertos insumos teóricos del republicanismo legal, una crítica al acuerdo reparatorio en el proceso penal chileno. Se utilizan los principales valores defendidos desde la óptica republicana para dar forma a una teoría que permita legitimar la práctica procesal penal y, en ese contexto, evaluar las condiciones de aprobación del acuerdo reparatorio como su extensión dentro del derecho procesal.
\end{abstract}

PALABRAS CLAVE Acuerdo reparatorio, proceso penal, republicanismo legal, filosofía política, legitimación del proceso penal.

ABSTRACT This article focuses on defining, assuming certain theoretical inputs of legal republicanism, a critique of the reparatory agreement in the Chilean criminal process. The main values defended from the republican point of view are used to shape a theory that allows to legitimize the criminal procedural practice and, in that context, evaluate the conditions of approval of the reparatory agreement as its extension within the procedural law.

KEYWORDS Reratory agreement, criminal process, legal republicanism. 


\section{Introducción}

En el derecho procesal penal no es común dar cuenta de la necesidad de recurrir a la filosofía moral desde la dogmática legal en sus diversas manifestaciones. El derecho procesal se ha mantenido, insanamente a mi juicio, casi completamente al margen de esos intentos, en que el derecho civil y penal llevan una delantera notable. ${ }^{1}$

En este trabajo, quisiera adentrarme en un problema relevante para la conceptualización de un proceso penal desde el punto de vista de su legitimidad. Se trata del recurso a una teoría moral que impacte en la justificación de sus instituciones y, en particular, en una de ellas: el acuerdo reparatorio. ${ }^{2}$

Particularmente, quisiera enfocar mi atención en una institución que me parece relevante de analizar bajo este prisma, ya que el acuerdo reparatorio regulado en el artículo 241 del Código Procesal Penal tiene, a mi juicio, la propiedad de reunir pretensiones de claro corte contractual en el marco de la realización del plan punitivo

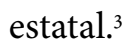

1. Aunque, ciertamente, este es un cometido que, desde cierto punto de vista, permanece pendiente para el derecho. En este sentido, creo que lo señalado por Cortina hace algún tiempo se encuentra plenamente vigente, y resta aún en el ámbito del derecho dar cuenta de la necesidad de contar con una determinada filosofía moral que permita enfrentar problemas de justificación práctica de las instituciones. Para más información, véase Cortina (1985). Un primer intento por vincular estos puntos puede encontrarse en Valenzuela (2017).

2. Con particular interés, puede observarse esta necesidad de buscar los fundamentos de las instituciones en el derecho procesal penal a través del sugerente pasaje de Carnelutti (1960: 13-22): «Había una vez tres hermanas que tenían en común, por lo menos, uno de sus progenitores: Se llamaban la ciencia del derecho penal, la ciencia del proceso penal y la ciencia del proceso civil. Y ocurrió que la segunda, en comparación con las otras dos, que eran más bellas y prósperas, había tenido una infancia y una adolescencia desdichadas».

3. «Artículo 241. Procedencia de los acuerdos reparatorios. El imputado y la víctima podrán convenir acuerdos reparatorios, los que el juez de garantía aprobará, en audiencia a la que citará a los intervinientes para escuchar sus planteamientos, si verificare que los concurrentes al acuerdo hubieren prestado su consentimiento en forma libre y con pleno conocimiento de sus derechos. Los acuerdos reparatorios solo podrán referirse a hechos investigados que afectaren bienes jurídicos disponibles de carácter patrimonial, consistieren en lesiones menos graves o constituyeren delitos culposos. En consecuencia, de oficio o a petición del ministerio público, el juez negará aprobación a los acuerdos reparatorios convenidos en procedimientos que versaren sobre hechos diversos de los previstos en el inciso que antecede, o si el consentimiento de los que lo hubieren celebrado no apareciere libremente prestado, o si existiere un interés público prevalente en la continuación de la persecución penal. Se entenderá especialmente que concurre este interés si el imputado hubiere incurrido reiteradamente en hechos como los que se investigaren en el caso particular». 
Con respecto a esta institución, el legislador ha regulado también los efectos penales del mismo (artículo 242) ${ }^{4}$ y sus efectos civiles (artículo 243). ${ }^{5}$ El artículo 244 regula el llamado efecto subjetivo del acuerdo reparatorio. ${ }^{6}$

La revisión de argumentos de este trabajo no busca ser una reconstrucción cabal de lo que debemos entender por «republicano» o «neorepublicano» en el escenario de la discusión filosófico-política. Buscaremos utilizar algunos argumentos del ámbito filosófico moral en el campo del derecho procesal penal.

Al mismo tiempo, se busca enfrentar al acuerdo reparatorio, asumida la capacidad que muestra en tanto institución de reunir pretensiones de corte claramente contractual en el marco del desarrollo del ius puniendi estatal. Esto resulta interesante, ya que, en nuestro sistema procesal penal, no existe otra institución que marque una distinción clara entre pretensiones contractuales o de derecho privado y pretensiones punitivas marcadamente, por tanto, públicas.

Para lo anterior, primero describiré al republicanismo legal, sus valores principales y cómo ellos desembocan en una teoría moral para el proceso penal.

Luego, me referiré al acuerdo reparatorio frente a estas ideas republicanas para, finalmente, ofrecer algunas consideraciones críticas en torno a la interpretación de las ideas de libertad e igualdad a propósito del acuerdo reparatorio, así como a su extensión dentro de nuestro sistema.

Así, los apartados de «El republicanismo legal frente al proceso penal»y «Una teoría republicana del derecho penal y procesal penal» son introductorios y buscan establecer un contexto de discusión necesario en el estudio de las instituciones procesales. El resto de los apartados buscan mostrar cómo los argumentos generales revisados pueden proyectarse en ciertas instituciones del proceso penal, en este caso, el acuerdo reparatorio.

\section{El republicanismo legal frente al proceso penal}

El republicanismo es una teoría de la justicia política que tiene su origen en ideas que modelaron las primeras concepciones de «república».

4. «Artículo 242. Efectos penales del acuerdo reparatorio. Una vez cumplidas las obligaciones contraídas por el imputado en el acuerdo reparatorio o garantizadas debidamente a satisfacción de la víctima, el tribunal dictará sobreseimiento definitivo, total o parcial, en la causa, con lo que se extinguirá, total o parcialmente, la responsabilidad penal del imputado que lo hubiere celebrado».

5. «Artículo 243. Efectos civiles del acuerdo reparatorio. Ejecutoriada la resolución judicial que aprobare el acuerdo reparatorio, podrá solicitarse su cumplimiento ante el juez de garantía con arreglo a lo establecido en los artículos 233 y siguientes del Código de Procedimiento Civil. El acuerdo reparatorio no podrá ser dejado sin efecto por ninguna acción civil».

6. «Artículo 244. Efectos subjetivos del acuerdo reparatorio. Si en la causa existiere pluralidad de imputados o víctimas, el procedimiento continuará con respecto a quienes no hubieren concurrido al acuerdo». 
Es complejo entregar una noción absoluta de republicanismo, pero probablemente se deba destacar su vocación «histórica». Es posible que, como ideario, sea identificado con muchos autores que puede que también soportaran una clasificación «liberal» $\mathrm{o}$ «comunitarista». Quizás, un punto interesante para comenzar a comprender a la concepción republicana tiene relación con su marcada tendencia «antitiránica» (Gargarella, 1999: 163).

Además, el republicanismo suele estar construido como una teoría de la justicia política que busca la consecución de la libertad de la república por medio del ejercicio de virtudes cívicas. ${ }^{7}$

Con independencia de la amplitud muchas veces excesiva del concepto de republicanismo, desde la perspectiva de la relevancia en el debate filosófico político, esta teoría se ha erigido como la gran agenda contrapuesta al liberalismo. Resulta llamativo que, además, el republicanismo, a diferencia de otras teorías morales, haya dedicado claros argumentos para concebir al derecho. De hecho, muchos de los argumentos que constituyen las primeras versiones del denominado republicanismo legal tienen lugar a propósito de la conceptualización de la pena y el castigo en la sociedad. ${ }^{8}$

Es claro que el republicanismo, como teoría política, se construye fuera de los márgenes del derecho. Por esto, podemos hablar de republicanismo por un lado y de republicanismo jurídico (legal republicanism) por otro. Esto no supone dejar de lado los argumentos y la perspectiva sostenida desde este tipo de filosofía para instituciones concretas del ámbito jurídico. ${ }^{9}$

Así las cosas, pueden identificarse ciertos rasgos preeminentes de esta corriente de justicia política de cara al análisis jurídico: la libertad (en su variación propiamente republicana, es decir, libertad como no-dominación), la igualdad, el autogobierno, las virtudes cívicas o la ciudadanía activa. ${ }^{10}$

7. La lista de las virtudes cívicas relevantes para el republicanismo es prácticamente inalcanzable. Pueden destacarse el coraje, como actitud de defensa de la república, y la prudencia en la participación del gobierno. Véase Gargarella (1999: 164). Una revisión de la noción de libertad republicana puede encontrarse en Costa (2009: 401-419).

8. Así, Besson y Martí (2009: 3). Podría dudarse de la pertinencia de los argumentos republicanos creados en contextos normativos diferentes al nuestro. El ámbito anglosajón tiene claras diferencias con nuestra tradición continental. Sin embargo, debe tenerse en cuenta que lo relevante para efectos de nuestra tradición jurídica son los argumentos generales que ciertamente pueden impactar la comprensión de nuestras instituciones y prácticas. Debe consignarse que la idea de República en este contexto parece contar con, además, una necesidad de justificación epistémica (dada esta intensa vocación jurídica). Véase Moreso (2009: 315-322).

9. Podría pensarse que en realidad se trata tan solo de argumentos de corte político general y que no tienen una clara vocación jurídica. Creo que este punto de vista sería erróneo. Como afirmó Pettit, la política, las decisiones políticas y la filosofía política se relacionan estrechamente con «lo normativo»: la política se conduce ineluctablemente por el lenguaje normativo. Véase Pettit (1999: 18).

10. Este esquema está presente en Besson y Martí (2009: 10). Sobre esas características de las teorías 


\section{La libertad republicana}

Muchos consideran que la idea central del republicanismo es una particular concepción de la libertad. La formulación más conocida de la libertad republicana es la ofrecida por Philip Pettit (Besson y Martí, 2009: 13; Pettit, 1999, 2005, 2006).

$\mathrm{El}$ autor constata la relevancia de la clásica distinción entre libertad negativa y libertad positiva realizada por Berlin. Realiza una lectura en la que esa distinción resulta poco útil para explicar las acciones libres por parte de los ciudadanos. Por ello, sostiene que:

La distinción libertad negativa-positiva ha hecho un mal servicio al pensamiento político. Ha alimentado la ilusión filosófica de que, detalles aparte, solo hay dos modos de entender la libertad: de acuerdo con el primero, la libertad consiste en la ausencia de obstáculos externos a la elección individual; de acuerdo con el segundo, entraña la presencia, y normalmente el ejercicio, de las cosas y las actividades que fomentan el autodominio y la autorrealización: en particular, la presencia y el ejercicio de las actividades participativas y de sufragio, merced a las cuales los individuos pueden unirse a otros en la formación de una voluntad común, popular (Pettit, 1999: 37).

El concepto planteado por Pettit es una especie de síntesis de las ideas que se encuentran entrelazadas en la dicotomía libertad negativa-positiva propuesta por Berlin. De este modo, Pettit (1999: 40-41) sostiene que:

El mejor modo de introducir la libertad como no-dominación puede ser observar que la taxonomía berliniana de libertad positiva y negativa excluye una tercera posibilidad más o menos llamativa. Él piensa en la libertad positiva como autodominio y en la libertad negativa como ausencia de interferencia por parte de otros. Pero dominio e interferencia no son equivalentes. ¿No hay, pues, la posibilidad intermedia de que la libertad consista en una ausencia - como quiere la concepción negativa-, pero en una ausencia de dominio por otros, no en una ausencia de interferencia? Esta posibilidad tendría un elemento conceptual en común con la concepción negativa -el foco en la ausencia, no en la presencia-, y un elemento en común con la positiva: el foco en la dominación, no en la interferencia.

Como también apuntan Besson y Martí (2009: 14), la libertad como no-dominación puede ser considerada una tercera alternativa dentro del mapa clásico de libertad negativa o positiva. ${ }^{11}$

Esta idea de libertad no consiste en una razón de inhibición de acciones de parte de terceros, entendidas como interferencia en el caso de la libertad negativa, y no depende exclusivamente del dominio de sí mismo que entraña la libertad positiva. La

republicanas puede consultarse también Viroli (2001: 5-14).

11. Véase también Walker (2006: 237-259) y Markell (2008: 9-36). 
libertad como no-dominación intenta reunir rasgos de ambos conceptos de libertad (la interferencia y la dominación).

Puede haber interferencia entre los sujetos de una determinada comunidad, pero para que esta sea considerada indeseable deberá ser arbitraria. Es decir, no toda interferencia en el plan de vida de los ciudadanos es en sí misma problemática. Por otra parte, la idea de libertad como no-dominación se construye sobre la base del dominio. No debe haber dominio de parte de terceros, tomando, de esta manera, un enfoque propio de las concepciones de libertad positiva.

Sin embargo, la posibilidad de concebir a la libertad de esta manera intermedia puede ser un buen ejercicio de comprensión de la concepción negativa y positiva de libertad, pero no determinan que el concepto de libertad, como no-dominación, tenga sentido por sí mismo.

La concepción de libertad como no-dominación debe distinguirse claramente de la dicotomía berliniana, es decir, no debe ser tan solo un ejercicio conceptual tributario de una manera de entender a la libertad bajo el esquema de libertad negativa o positiva.

Para esto, Pettit considera primero la relación entre no-dominación y autodominio. Para el autor, la ausencia de dominación no garantiza el logro del autocontrol. La dominación queda ejemplificada por la relación entre el amo y el esclavo. La parte dominante, en una relación de este tipo, puede interferir arbitrariamente y con impunidad en las decisiones de la parte dominada (Pettit, 1999: 41).

Es posible tener dominación sin interferencia y también interferencia sin dominación. Puedo ser esclavo de otro sin que ese otro interfiera en ninguna de mis decisiones. Se sufre dominación cuando se tiene un amo. Se disfruta de no-interferencia cuando el amo no consigue ser obstáculo en las decisiones del esclavo (Pettit, 1999: 42).

Es habitual encontrar casos en que puede padecerse interferencia sin sufrir dominación. Una institución o una persona pueden interferir en las decisiones de un sujeto en pos de sus propios intereses, por ejemplo. Puede darse que esa interferencia se relacione con condiciones como el acuerdo o el tomar en cuenta la opinión de quien se ve interferido. En este caso, si la condición para interferir no se cumple, puede entenderse condenable a la acción que constituye la interferencia.

Una interferencia así entendida no puede ser señalada como dominación. La dominación tiene, como propiedad central, una determinada capacidad para intervenir en los asuntos de otro, aunque no se interfiera. La interferencia no necesita ese «estatuto» y puede verificarse de manera arbitraria o no. La dominación en esta óptica puede producirse con independencia de la interferencia en la vida de otro.

Dado que interferencia y dominación son dos males distintos, Pettit (1999: 42) considera que la no-interferencia y la no-dominación deben ser dos ideales distintos.

Pueden existir relaciones donde podamos decir que hay dominación y en esa relación puede haber interferencia o no. Luego, puede haber interferencia y esta puede darse en el marco de la dominación o no. También pueden existir relaciones donde 
no haya ni dominación ni interferencia, y relaciones donde confluyan la dominación y la interferencia.

Un estado de «no-interferencia» es eludir la coerción en el mundo real. Parece ser que la manera en que la vida social se despliega supone, siempre, soportar interferencias en el desarrollo de la misma. ${ }^{12}$

Ahora, ¿qué es necesario para que en un contexto de no-interferencia tampoco haya dominación? La respuesta de Pettit es que debería haber un contexto en donde los débiles sean defendidos de los poderosos. Esto resulta sumamente sugerente. A diferencia de la perspectiva liberal, el mantenimiento de una idea de libertad asociada a los ideales de no-dominación y no-interferencia permiten considerar una actitud de parte de quienes tienen mayores posibilidades de violar estos ideales en orden a protegerlos. Es decir, sobre todo concierne a los poderosos tener una actividad que permita que los ciudadanos sean efectivamente libres. Como veremos, esto resulta importante de cara a la comprensión del acuerdo reparatorio en material penal. ${ }^{13}$

Un rasgo importante de esta concepción de libertad como no-dominación es que puede perderse aun sin padecer interferencia. Por otra parte, puede haber interferencia sin que haya pérdida de libertad. Esto ocurre cuando la interferencia no es arbitraria y no representa una forma de dominación (Pettit, 1999: 56).

La interferencia no es arbitraria cuando está controlada tanto por los intereses como por las opiniones de los afectados, y es requerida para servir esos intereses conforme a esas opiniones.

Esto es claro a la hora de considerar al derecho, que es una forma de interferencia por definición. La regulación de la conducta y la existencia de reglas como razones para la acción constituyen, sin duda, una interferencia en el ámbito de los sujetos en la comunidad. La relación entre delito y vigencia del derecho se muestra particularmente clara, ya que la interferencia en la vida de la víctima que supone la realización del delito tiene por respuesta un marco de intervención para producir un dictamen acerca de la arbitrariedad de los hechos padecidos. Luego, veremos que esto tiene relevancia si nos preguntamos acerca de la legitimidad de un acuerdo reparatorio en el marco del uso de la punición estatal.

Las reglas del derecho pueden ser consideradas una clase de interferencia que permite el aseguramiento de la libertad. No estamos frente al argumento, tradicio-

12. Una interesante revisión crítica de esta idea se encuentra en Skinner (2010: 95-102).

13. Podría pensarse que la concepción de libertad republicana es una clase de libertad positiva. Pettit niega esta característica. Para él, las formulaciones originarias en materia de libertad republicana, es decir, la concepción romana o la concepción de Maquiavelo, por ejemplo, no ponían el énfasis en el ejercicio de la libertad como un apoyo para ejercer la dominación. Al contrario, lo que el concepto de libertad entrañaba en estas formulaciones era más bien la idea de defensa, de seguridad, es decir, la nodominación (1999: 47). 
nalmente liberal, de que por medio del derecho coartamos a la libertad para dejar un espacio seguro de ejercicio de la misma. Para los republicanos, esta forma de interferencia es constitutiva de la libertad, lo que descarta la retórica de las compensaciones, esa idea de dar un paso atrás para dar dos adelante (Pettit, 1999: 57).

\section{Igualdad republicana}

La igualdad es vista como una precondición de la libertad. La cuestión central es que, desde la perspectiva republicana, no puede haber ciudadanos más libres que otros (Besson y Martí, 2009: 18-19).

Es importante introducir una distinción para la comprensión de la idea de igualdad republicana. Por una parte, la igualdad debe neutralizar la inequidad socioeconómica. El republicanismo postula el dar poder a los débiles y, sobre todo, la posibilidad de que los sectores más pobres de la población vean cubiertas sus necesidades básicas. ${ }^{14}$

Por otra parte, la concepción republicana de la igualdad involucra una muy fuerte comprensión de la democracia y, con ello, de la participación ciudadana. Esto conlleva remover los obstáculos para que la deliberación sea llevada a cabo, lo que implica la primera de las dimensiones de la igualdad (Besson y Martí, 1999: 20).

Este no es simplemente un criterio de justicia distributiva, aunque es evidente que la ejecución de un plan igualitario bajo el esquema republicano tendrá consecuencias de distribución equitativa de los medios de subsistencia.

En un sentido, la igualdad republicana es funcional a la libertad. Parece ser un valor que tiene por función central equiparar las posibilidades de participación y dotar de proyección, en la realidad, a la concepción de democracia deliberativa.

La óptica republicana se expresa en la comprensión de la incidencia que tienen los ciudadanos en el gobierno. De esta manera, lo relevante es determinar cómo los ciudadanos pueden ser capaces de gobernar autónomamente su destino.

La concepción de democracia que emana del modelo republicano puede ser calificada como exigente. Es decir, es una tesis que asume un abierto e intenso compromiso con la participación ciudadana, acorde, por cierto, con la concepción del derecho como producto del acuerdo o de la voluntad de los integrantes de la comunidad.

La idea central para estudiar el ideal de democracia deliberativa asociado al republicanismo es la deliberación, que es un proceso por el cual se intenta llegar a una decisión. Es un acto de comunicación colectiva, ya que involucra a todos los miembros de una determinada comunidad. Además, es un acto reflexivo en el que deberían intercambiarse razones que cuenten como argumentos a favor o en contra de una determinada propuesta o un conjunto de ellas, con la finalidad de convencer racionalmente a los demás (Martí, 2006: 24).

14. Un interesante punto de vista al respecto se puede ver en Van der Rijt (2009: 465-492). 
Este proceso ha sido concebido como uno donde, además, los integrantes de la comunidad deben actuar movidos por la imparcialidad en sus juicios y valoraciones.

Un rasgo extremadamente importante es que este proceso es ideal. Con esto, se señala que permite describir una democracia en términos de ideal, es decir, en términos de cómo debería funcionar la democracia en una determinada comunidad.

Como puede apreciarse, instituciones que descansen en el autogobierno y que sean compatibles con las ideas de libertad como no-dominación e igualdad republicana deberían ser deseables en el contexto jurídico. Una determinada lectura del acuerdo reparatorio lo puede volver compatible en este sentido: si lo vemos como un acuerdo que tiende a reconocer igualitariamente a quienes concurren al acuerdo y resulta de un ejercicio deliberativo, puede constituirse en una herramienta poderosa para reconocer la vigencia del sistema jurídico.

\section{Una teoría republicana del derecho penal y procesal penal}

Hasta aquí, resumidamente, hemos visitado los rasgos principales de la teoría republicana de cara al derecho. Ahora, corresponde que centremos esas ideas en el campo concreto del derecho penal y procesal penal, ya que quisiera revisar el acuerdo reparatorio a la luz de estas consideraciones.

Creo que los argumentos del republicanismo son especialmente relevantes para el derecho penal y procesal penal. El ejercicio de la punición estatal ha sido objeto de atención de parte de los filósofos políticos y del derecho que trabajan desde la perspectiva republicana. Se trata de la teoría política con mayores vínculos con la práctica punitiva estatal. ${ }^{15}$

Por lo general, se comprende la relación entre política y derecho penal a través de la etiqueta «política criminal». Me parece que establecer la conexión entre el contexto de justificación, propio de una teoría política como el republicanismo, y el derecho penal en sentido amplio, se inscribe dentro de ese esfuerzo "político- criminal». En este sentido, el republicanismo tiene una clara vocación jurídica y quisiera remarcar que esa vocación es, a su vez, marcadamente penal.

Ha resultado relativamente natural que aquellos que se dedican al estudio del derecho y que asumen un compromiso republicano hayan «probado» las tesis más generales del republicanismo en ciertos puntos concretos del derecho. Esto contrasta, en cambio, con la visión de los juristas que, sobre todo en el contexto latinoamericano, no hemos realizado una revisión acabada de los argumentos que pudieran ser útiles para comprender e interpretar mejor nuestras instituciones.

Creo que el derecho penal es un campo de múltiples problemas para el análisis de

15. Ciertamente, la evidencia más notoria la ofrecen los trabajos de Braithwaite y Pettit (1990), Martí (2009) y Dagger (2008a, 2008b, 2009). 
las cuestiones de filosofía política, principalmente por el lugar común ya apuntado: el derecho penal parece estar indisolublemente asociado al corolario de las ideas ilustradas. Y, ciertamente, no puede hablarse con claridad del derecho penal sin considerar, en el esquema continental, al proceso penal. Debemos notar que los argumentos que hemos ido enfrentando en este trabajo tienen un claro contexto de producción en el ámbito anglosajón. Por esto, debemos dar cuenta de la noción ampliamente extendida en ese ámbito, que permite sostener que derecho penal es capaz de designar sin problema tanto lo que los continentales llamaríamos «derecho penal sustantivo» como lo que solemos llamar «derecho procesal penal». En estas páginas, mi interés es abordar los alcances de esta perspectiva para el muy concreto caso del acuerdo reparatorio en el proceso penal chileno.

Podemos hablar, entonces, de un destacado republicanismo penal. Con esto, podemos denotar que el republicanismo «jurídico» utiliza una plataforma concreta, como es el derecho penal y, con ello, asume la necesidad de dotar de sentido su ideario más abstracto en lo que pueda ser conducente dentro de la explicación de un sector del derecho determinado.

Bratihwaite y Pettit (1990: 1) consideran que lo que pretenden realizar es una «teoría comprehensiva» del derecho penal. Una teoría comprehensiva supone sostener una tesis teleológica del uso del derecho penal, es decir, alcanza al proceso.

Por esto, Braithwaite y Pettit piensan en la posibilidad de impactar en el diseño de la política criminal. Lo interesante para una teoría acerca del derecho penal es permitir la generación de argumentos en torno a las decisiones de configuración general del mismo, teniendo para ello, como terreno natural, el de la política criminal.

Sin embargo, esta no es la única manera en que una teoría republicana puede influir en el estudio del derecho penal.

Es posible contar con una teoría republicana del derecho penal que tenga proyecciones en la fundamentación de las instituciones del sistema de justicia penal.

Estas ideas se desenvuelven no solo en el ámbito de la teoría de la pena, sino que también deben tomar en consideración las cuestiones de fundamentación del proceso penal, como veremos a propósito del acuerdo reparatorio en Chile.

Richard Dagger advierte que, desde la perspectiva republicana, pueden encontrarse tres concepciones de derecho penal. Las revisaremos a continuación (Dagger, 2009: 153).

\section{El delito como amenaza de dominación}

Esta aproximación al delito como amenaza de dominación está presente en el trabajo de Phillip Pettit, en particular en el libro citado Not Just Desert: A Republican Theory of Criminal Justice, escrito en colaboración con John Braithwaite. 
Descansa en la propuesta general de Pettit de concebir a la libertad como nodominación y como el valor político supremo.

La concepción de libertad como no-dominación tiene impacto en una teoría normativa general del derecho penal. En ella, esencialmente, el crimen constituye una invasión en el ámbito de dominio de la víctima (Dagger, 2009: 154).

Por supuesto, la invasión toma la forma de una interferencia arbitraria, que puede recaer en la persona (como en el homicidio y la violación), en la competencia o determinación (como en el secuestro, el acoso o las coacciones), o en la propiedad (como en el robo).

Lo relevante en la concepción de delito republicana es la «invasión» que sufre la víctima por parte del autor del delito. Esta interferencia es arbitraria y deviene en un quiebre en el dominio que tiene la víctima de sus intereses.

Para Dagger (2009: 155), es evidente que cualquier teoría del derecho penal que tenga como base en su concepción del delito a la libertad como no-dominación y que con ello deba identificar al delito como un acto de dominación, deber ser calificada como una teoría republicana.

\section{La virtud republicana y el vicio criminal}

Otra manera de ver la concepción republicana en materia de derecho penal es considerar que el concepto central para entender el delito no es la dominación (o la derivación del delito como una amenaza de dominación), sino la virtud.

Esta idea tiene importancia para justificar ciertas obligaciones penales de acción, como la evitación de delitos ante terceros, el auxilio y los delitos contra la administración de justicia, entre otros.

Para esta perspectiva, el delito se configura no solo de acuerdo con la valoración negativa de él o los hechos que lo constituyen, sino que, además, involucra las acciones positivamente valoradas que pudieron haberse ejecutado en las circunstancias en las que, en cambio, se cometió un delito (Dagger, 2009: 156).

La exigibilidad de cierta conducta, desde la perspectiva republicana, se conecta con la idea de virtudes. Es a través de la comprensión de la actividad ciudadana como una actividad que normativamente debe dirigirse al bien, o a la promoción de aquellos valores que consideremos buenos, que podemos identificar al delito como una medida de conducta que implique una desviación o una motivación defectuosa.

\section{El delito como mal compartido}

Esta tesis puede adjudicarse a Duff y Marshall. Si bien es posible sostener que esta postura se inscribe en un tipo de comunitarismo o en una correcta amalgama entre liberalismo y comunitarismo, también podría ser identificada como republicana (Duff y Marshall, 1998; Dagger, 2009: 159). 
El foco está situado sobre los denominados «delitos paradigmáticos» (como el homicidio, la violación y el robo, entre otros), considerados crímenes que pueden ser reconocidos por medio de una victimización directa. Existe una clase de crímenes que pueden ser reconocidos fácilmente como el núcleo duro del derecho penal.

De acuerdo con esta tesis, el crimen implica ciertas conductas socialmente proscritas que implican un problema «público». Algunas de estas conductas pueden darse en el mundo de manera que, sin una calificación jurídica (mediante una prohibición penal), podrían ser consideradas conductas desprovistas de la calificación de erróneas. Es el caso de conducir sin licencia. Puede conducirse un vehículo sin licencia y esto no implica actuar dentro de los límites de lo proscrito socialmente o, al menos, el tipo de juicio de reproche que puede realizarse por la comunidad ante alguien que conduzca sin licencia difiere ostensiblemente con respecto al que mata o viola a otro.

Existen ciertas conductas que no admiten otra calificación que la criminal. Existen conductas malas en sí mismas. Esta clase de conductas son identificadas prima facie por los miembros de la sociedad como conductas proscritas. Si un sujeto observa que otro golpea a su oponente de manera brutal, no tendrá que recurrir a su conocimiento de la proscripción de la tentativa de homicidio para considerar que esa acción se encuentra bajo el supuesto de lo proscrito socialmente (Dagger, 2009: 159).

Lo determinante es que, para este enfoque, la clase de conductas malas in se constituyen un asunto público, son portadoras de un mal público. Los ciudadanos, al verificar la existencia de una conducta constitutiva de delito, considerarán necesaria una acción de la sociedad que marque al delito como un mal o, en otros términos, considerarán razonable censurar penalmente a esta clase de mal que les concierne.

La principal propiedad de esta posición radica en sostener que el crimen implica o vincula a los ciudadanos por definición (al menos el crimen mala in se). No puede explicarse coherentemente el derecho penal «duro» como una clase de conflicto que pertenece única y exclusivamente a quienes participan directamente en él.

Esta visión también conlleva sostener que el delito se pena principalmente por el daño causado a la víctima. No se sanciona al violador para convencer a futuros violadores de que no lo hagan o porque el violador obtendría una ventaja injusta si le dejásemos sin sanción, se le sanciona por lo que ha hecho, porque el delito tiene en sí mismo un sentido que no soporta ser justificado sin considerar este carácter (Marshall y Duff, 1998: 12).

En este enfoque, el siguiente paso es considerar que el mal del delito es un mal compartido. Aquí, se apela a la consideración relativa de que el estatuto de víctima es en un sentido contingente. Por esto, los ciudadanos pueden considerar que ellos también podrían haber sido víctimas del delito. El mal que ocasiona el delito no es visto como el mal de la víctima, sino como nuestro mal.

Marshall y Duff utilizan el ejemplo de una violación. ¿Cómo reaccionaría un grupo de mujeres ante un ataque sexual en contra de una de ellas? Lo más probable es 
que con rechazo a la agresión y, como mínimo, sin indiferencia. Este es el camino que debería seguirse para sostener el carácter público del delito, el mal que ocasiona es compartido (Marshall y Duff, 1998: 18-22).

El mal que está implícito en el delito no es un mal ajeno para el ciudadano que lo presencia y que puede intervenir sin riesgo propio o ajeno. Esto, en un sentido, se debe a que el mal es también del espectador.

Este enfoque demuestra cómo los denominados delitos mala in se pueden ser concebidos como actos que generan un mal compartido tanto por la víctima como por la sociedad que presencia el hecho (Dagger, 2009: 161).

La noción de «males públicos» parece relacionarse directamente con una cierta intuición moral. Esto quiere decir que allí donde los denominados crímenes mala in se comportan un juicio valorativo (negativo), vemos con mayor fuerza la posibilidad de «empatía» en términos de concepción política y, subsecuentemente, jurídica. Dicho de otro modo, el delito de homicidio es evidentemente un delito más intuitivo como mal en sí mismo que la evasión de impuestos.

Esto no significa que el delito de evasión de impuestos no pueda ser concebido como un delito bajo el prisma del mal compartido. Al contrario, aparecería como un ejemplo bastante obvio, ya que el incumplimiento de las obligaciones tributarias de parte de un ciudadano es visto, evidentemente, como un asunto que nos compete a los demás ciudadanos.

La cuestión está en que el esfuerzo debe centrarse en el denominado «núcleo duro» del derecho penal. Esto, porque este núcleo es el que tiene la mayor carga moral en el nivel de la comprensión de los ciudadanos. Esta noción puede ser útil para analizar el acuerdo reparatorio desde el punto de vista de los delitos que permitirían que las intervinientes en el proceso puedan acordar eficazmente condiciones de reparación que terminen con el proceso penal. Parece ser que la idea de usar delitos de baja penalidad o culposos tiene detrás esta intuición relativa a la existencia de crimina mala in se, en los que no existiría claridad para dar a los intervinientes ese espacio de libertad contractual propio del acuerdo reparatorio.

\section{El acuerdo reparatorio ante el republicanismo legal}

Una visión como la que ha sido expuesta en estas páginas puede ser de utilidad para la comprensión del proceso penal en términos abstractos. En general, no es claro el sentido que las instituciones procesales tienen de cara a su justificación filosóficopolítica y esta definición resulta necesaria en términos, al menos, teóricos. ${ }^{16}$

El proceso penal expresa un modo de «llamar a rendir cuentas» a los infractores

16. Aunque desde un inicio el acuerdo reparatorio dio lugar a reflexiones en torno a su naturaleza reparatoria y no punitiva. Para más información, véase Videla (2010). 
al derecho penal, el que, a su vez, expresa una serie de relevantes acuerdos morales sobre las acciones toleradas y las rechazadas en la vida social. Es un escenario de importancia para comprender la configuración de los acuerdos sociales en general.

Sin embargo, una visión en la que se haga explícito el alcance filosófico moral de las instituciones ofrece, también, un grupo de argumentos específicos sobre el sentido de cierto diseño institucional en materia procesal penal.

La idea de garantía en el proceso penal ha sido concebida como un argumento defensivo del ciudadano frente al ejercicio de la potestad pública de sancionar. De hecho, existe cierta literatura en materia de derecho penal y proceso penal que considera, como punto indiscutible, la existencia de garantías liberales cuando se trata de esta forma de derecho. ${ }^{17}$

De hecho, en el solo ámbito procesal penal existe una clara corriente que puede llamarse «garantismo», a partir de la idea de defensa de una determinada concepción de los derechos y libertades ciudadanas en el ámbito penal. Esta corriente encuentra sus lineamientos principales en una visión abiertamente liberal del derecho y manifiesta un compromiso, muchas veces implícito, con el ideario del liberalismo político. ${ }^{18}$

Desde un punto de vista republicano, esta noción no puede ser ignorada. Una visión de las garantías penales de raigambre liberal asume una relación tiránica entre el derecho y los ciudadanos que no puede tener lugar en una concepción republicana. Un liberal tiende a considerar que el derecho - y en este caso el derecho procesal penal- es una herramienta a través de la cual el soberano interfiere en la vida de los ciudadanos. Con esto, asume que esa interferencia es, por naturaleza, extrínseca. ${ }^{19}$

17. En este sentido, por ejemplo, a propósito de la globalización y su impacto en los sistemas penales europeos, con respecto a la armonización de legislaciones penales Correcher (2013: 125) sostiene: «En sus rasgos relativos incluyan el respeto a los derechos y libertades que deben ser contemplados por el derecho penal, de acuerdo con la función garantista conferido a este desde su surgimiento a partir de la filosofía jurídica liberal».

18. Esta manera de concebir a las garantías como sección fundamental del proceso penal ha derivado en que incluso se cuestione el sentido «sancionatorio» del proceso penal y la pena. Por ejemplo, se ha señalado: «Podemos darnos una idea de la apreciación que un operador de justicia tenga del sistema penal, según lo considere un instrumento de represión, o bien un conjunto de garantías a favor de las personas que limitan el poder represivo del Estado. En otras palabras: si se cree que el sistema penal sirve para privar de la libertad a la persona estaremos ante un juez, fiscal, defensor, abogado, eminentemente represivo; pero si al contrario, lo concebimos como un conjunto de normas a favor del ciudadano, y limitante del poder del Estado, nos encontraremos ante un operador de justicia garantista» (Rosell, 2009: 2).

19. Por cierto, esto supone dar por correcta cierta conceptualización acerca del garantismo, aunque como se ha apuntado, «bajo el difuso concepto de garantismo caben (como ya se vio) muchas cosas. De allí que algunas precisiones básicas que se puedan hacer con respecto a esa noción son, sin duda, pertinentes. Empero, la enorme cantidad de clasificaciones y divisiones por las que apuesta Ferrajoli y, peor aún, la axiomatización de las tesis garantistas representa simplemente una pedantería, un juego 
Se asume que el ciudadano se protege del Estado, entendiendo que el uso de la facultad de sancionar penalmente es, en alguna medida, «ajena» a los ciudadanos a los que se les castiga.

Entonces, esta visión liberal provoca que, por un lado, se cuestione el sentido sancionador del proceso penal y la pena, intentando sostener que el proceso es una «garantía» para el ciudadano que será sancionado. De este modo, se diluye el sentido punitivo de la pena, convirtiendo al proceso penal, de un modo creciente, en un derecho de administración de medidas de seguridad.

A primera vista, una visión comprometida con esta clase de teoría moral impide la inclusión de métodos que cuestionen el sentido público del mal y del acto de enjuiciar y sancionar penalmente. Los denominados sistemas de resolución alternativa o colaborativa de conflictos, los arbitrajes o simplemente los acuerdos reparatorios, supondrían un cuestionamiento al sentido público del mal que subyace al sentido de las instituciones procesales penales.

Quienes han defendido la inserción de mecanismos de esta clase, han discutido la idea de «justicia» que se encuentra en el marco del proceso. Así, en su versión más conocida, se sostiene que existe una noción de justicia «restauradora» que se alzaría como un modo alternativo de observar lo que sus cultores suelen llamar el «conflicto penal». ${ }^{20}$

La importancia que para los defensores de este ideal de justicia tiene la noción de libertad privada e incluso de "propiedad» sobre el conflicto penal, resulta asombrosa. La noción tiránica del Estado con que se concibe a la justicia penal que viene a «despojar» a las partes de su posibilidad de acción específica para resolver, por sí mismos, los conflictos.

intelectual inútil. De lo que debiera tratarse, en cambio, es de ver si esas tesis tienen o no influencias, mayores o menores, en qué grados y de qué tipos, en los procesos penales concretos de un determinado ordenamiento jurídico» (Salas, 2012: 755).

2o. Así, se ha sostenido que una definición generalmente aceptada de justicia restaurativa es la proporcionada por Tony Marshall, quien señala que «la justicia restaurativa es un proceso a través del cual las partes que se han visto involucradas y/o que poseen un interés en un delito en particular, resuelven de manera colectiva la manera de lidiar con las consecuencias inmediatas de este y sus repercusiones para el futuro». Este concepto enfatiza dos principios o ideas centrales de la justicia restaurativa. Primero, se refiere a la inclusión de nuevos actores o partes en la resolución del conflicto jurídico-penal: la víctima, el autor, y otras personas afectadas por el delito como las familias de las partes y los miembros de la comunidad. En esta noción subyace la idea de que el delito no es solo un problema entre el Estado y el imputado, sino que, antes que nada, y como ha afirmado Nils Christie, es un conflicto entre las partes directamente afectadas por el delito, conflicto que ha sido históricamente usurpado a sus dueños por los profesionales de la justicia penal formal. Segundo, este concepto enfatiza la idea de la justicia restaurativa como un proceso participativo y deliberativo, que reúne - ojalá en un mismo lugar y mediante un encuentro personal- a las partes directamente afectadas por el delito a fin de que, a través del diálogo y la comunicación de hechos e intercambio de emociones, puedan llegar a un acuerdo mutuamente satisfactorio sobre cómo reparar el daño originado por el delito (Díaz, 2010: 2). 
Una teoría moral republicana no puede admitir este punto de vista. Los males que justifican la existencia del delito y de la justicia penal son públicos por definición.

De hecho, resultaría extremadamente discutible que razones de orden «económico» pudieran soportar la exigencia de justificación moral de las instituciones. Así, tanto la diluida concepción de «economía procesal» hasta las nociones de mayor interés como el análisis económico del derecho, y con ello la idea de eficiencia, deberían ser capaces de mostrarse lo suficientemente fuertes para llevar adelante un cuestionamiento relevante a la noción de libertad, de deberes y cargas públicas propias de un contexto moralmente exigente.

Pero una visión republicana puede darnos criterios para interpretar la institución a la luz de ciertos ideales y de una determinada forma de comprender al mal del delito.

Como hemos visto, el acuerdo reparatorio puede responder en sí mismo a la idea de libertad como no-dominación y de igualdad. Si lo interpretamos de este modo, el acuerdo reparatorio de nuestro Código Procesal Penal debería responder a la lógica del ejercicio de libertad de todo contrato: supone una clase de interferencia jurídicamente aceptada, pero niega la dominación de una parte a otra.

Así visto, esta condición supondría revisar, en el acuerdo mismo, las condiciones de interferencia y dominación posibles entre las partes. Solo de este modo se puede enfrentar el ideal igualitarista en el marco de ese mismo acuerdo. Como hemos visto, la noción republicana de igualdad supone una actividad clara dirigida a proteger al débil del poderoso. Esto quiere decir que, para evaluar al acuerdo reparatorio, debería ser importante verificar si el acuerdo se realiza en términos de resultar protector de los intereses de la parte más débil que concurre al mismo.

Además, la conducencia del acuerdo en ciertos delitos puede ser también cuestionada a la luz de una visión republicana que impacte en esta institución. Como sabemos el acuerdo reparatorio en Chile sólo se extiende a casos en se vean involucrados bienes jurídicos disponibles de carácter patrimonial, consistieren en lesiones menos graves o constituyeren delitos culposos.

Estos criterios podrían resultar ampliados en el marco de una tesis republicana como la que hemos explicado anteriormente. Si lo relevante es que el acuerdo se pueda realizar en el marco del ejercicio de la libertad y en un contexto igualitario, ¿por qué debería limitarse?

Como hemos dicho anteriormente, aparece la idea de «interés público» asociada a los crímenes y delitos que podrían responder este punto. Los delitos culposos, las lesiones menos graves y los delitos en los que se vea involucrado un bien jurídico de carácter patrimonial son de claro interés público. Es posible que con una óptica como la que hemos apuntado deba interpretarse la conducencia del acuerdo reparatorio teniendo como límite los denominados crimina mala in se, es decir, aquellos delitos donde parece que la voluntad de las partes deba ser dejada en segundo plano, ya que la intuición de la comunidad en esos delitos puede ser fuertemente punitiva. 
Ciertamente, la penalidad de los delitos contra la vida y la libertad pueden considerarse una guía para admitir estos acuerdos reparatorios. No obstante, si consideramos la idea de igualdad republicana ya apuntada, la verificación de condiciones de protección del débil ante el poderoso pueden ser también tenidas en cuenta. En esta medida, por ejemplo, la reparación por vía del acuerdo entre una empresa y los consumidores que hayan sufrido un daño por un producto defectuoso, podría ser cuestionable en la medida que no se introduzcan mecanismos de verificación de protección de intereses de los débiles.

Esto explicaría que los delitos contra intereses públicos colectivos, como los delitos funcionarios, no permitan admitir acuerdos reparatorios dado que en realidad, en ese contexto, el mal del delito se extiende a la comunidad y no pueden verificarse condiciones de acuerdo libre ni igualitario.

Entonces, existen tres criterios que pueden tenerse en cuenta para revisar la regulación del acuerdo reparatorio en nuestro sistema asumiendo la perspectiva republicana.

En primer lugar, debe tratarse de un acuerdo en el que la idea de libertad suponga no solo la autorrealización, sino que debe excluir estados de dominación entre uno y otro contratante. Así, lo dispuesto en el artículo 241 del Código Procesal penal debe ser visto como un acuerdo que tienda al ejercicio de la libertad como no-dominación. Esto supone que pueden admitirse interferencias derivadas tanto del escenario en el que se contrata (el proceso penal) como de los hechos que dan lugar al acuerdo (el delito). Lo que no debe admitirse son situaciones en las que se ponga en tela de juicio esta idea de exclusión de la dominación. En este punto, la regulación chilena no tiene grandes problemas al usar la fórmula «libre» y con «conocimiento de sus derechos».

En segundo lugar, debiera considerarse que el acuerdo reparatorio debe sujetarse al ideal igualitario, es decir, debe controlarse que se trate de un acuerdo que cuente con mecanismos de protección de los intereses de la parte débil frente a la parte más fuerte. Esto quiere decir que, en el acuerdo, debería darse espacio al control por parte del juez de las posiciones contractuales de las partes para poder afirmar la corrección y aprobación del acuerdo.

Este punto no se encuentra expresamente reconocido en nuestro ordenamiento. La idea de «derechos» asociada al acuerdo por las partes debería ser complementada con la idea de que el acuerdo se realice en términos igualitarios. La igualdad republicana, en este punto, requerirá que el acuerdo muestre activamente mecanismos de protección de los intereses de la parte débil. Ahí donde estructuralmente no sea posible esta clase de protección o simplemente no se dé lugar a ella, deberíamos entender que el acuerdo debe ser rechazado. ${ }^{21}$

21. Un enfoque crítico similar en torno a la intervención judicial por parte del juez puede encontrarse en Delgado y Carnevali (2020: 7): «Ahora bien, si partimos de la base de un juez natural, imparcial y 
Un tercer punto, relacionado con la idea de permisión por el legislador del acuerdo, es la pregunta relativa a los tipos de delitos que pueden ser objeto de acuerdo. Si tendiéramos a una regulación con mayores mecanismos de protección de la libertad y de la igualdad en los términos apuntados hasta aquí, podemos preguntarnos seriamente por una extensión de esta clase de acuerdos. Es claro que la idea de «bienes patrimoniales y disponibles» puede ser interpretada ampliamente, así como puede ocurrir en el caso de los delitos culposos, pero si lo relevante es que el acuerdo reparatorio pueda captar casos de ejercicio de la libertad igualitariamente controlados, ¿por qué no permitirlo en todos los casos? ${ }^{22}$

Quizá el límite que deba establecerse mira a ese núcleo de delitos en los que no se pretende la renuncia de la punición en su sentido tradicional, los llamados crimina mala in se. Podría, entonces, resultar aconsejable que el legislador definiera criterios en los que el delito objeto del proceso no permita simplemente el acuerdo, listando, entonces, lo que debe entenderse por crimina mala in se en el contexto procesal penal. ${ }^{23}$

\section{Conclusión}

A la luz de los argumentos expuestos, en primer lugar concluimos que debe destacarse la necesidad de recurrir al contexto de fundamentación filosófico, político y moral de las instituciones procesales, de modo de comprender de mejor manera a las mismas y para guiar su práctica. En este trabajo, hemos realizado una revisión somera de los principales argumentos disponibles en la tesis republicana aplicable al derecho, para visitar el sentido del acuerdo reparatorio en nuestro sistema procesal penal.

Este ejercicio es necesario en términos de una exploración en el contexto de justificación de las instituciones. En general, los filósofos políticos ofrecen comprensiones

predeterminado por ley, es importante delimitar bien qué funciones desarrolla y con qué objetivo, puesto que, la principal hipótesis que sostenemos en este trabajo es que le debe corresponder al juez un rol más activo en aquellas instancias en las que la situación jurídica permite que las partes desarrollen un rol protagónico frente al conflicto jurídico».

22. Esto podría verse reforzado con la idea de un juez que, en estos casos, promueva acuerdos y logre, entonces, un ejercicio igualitario de la libertad en estos casos. Sobre esta idea, véase Delgado y Carnevali (2020: 13).

23. Ciertamente, esto despertaría la pregunta sobre el sentido propiamente penal de esos delitos y la naturaleza de una respuesta privada como es en un sentido importante un acuerdo reparatorio. Sobre esto, vale la pena recordar el siguiente pasaje de Bovino (1998: 115): «Mecanismos como la reparación como causa de extinción de la acción penal pública reconocen los efectos negativos de la intervención penal, y la necesidad de atender los intereses de la víctima. Si ello es así, resultaría más razonable la descriminalización de aquellos hechos solucionables por esa vía y el establecimiento del tratamiento civil del caso - aun con la posibilidad de recurrir a reparaciones punitivas como las del derecho privado anglosajón- en donde resulta posible determinar que se pague el valor real de la reparación multiplicado por tres, en el marco del derecho privado». 
amplias y que se sujetan a patrones teóricos que no suelen tenerse a la vista en el escenario institucional. Este contexto debería incluirse, de manera de proyectar esas consideraciones en ámbitos concretos del derecho.

El republicanismo legal es particularmente interesante para este ejercicio de estudio de instituciones penales y procesales penales dada su intensa vocación por enfrentar el fenómeno del castigo estatal. Este fenómeno es particularmente claro si se sigue la óptica defendida por Braithwaite y Pettit en torno a una justificación utilitaria de la pena y la literatura que le sucedió.

El estudio del derecho penal y procesal penal requieren una adopción de posición en términos del sentido del castigo que excede los clásicos puntos de vista de la teoría de la pena. El castigo es una práctica social que requiere fundamentación y es clarificador revisar el sentido de las instituciones a la luz de esas razones que les justifican en términos abstractos.

En este sentido, creo que el acuerdo reparatorio ofrece particularidades conceptuales, ya que se trata de un contrato inserto en el contexto de desarrollo de la persecución penal. Así, la lectura desde el republicanismo, en particular desde la noción de libertad como no-dominación y de igualdad, resultan buenos insumos para dotar de sentido a la sujeción de ese contrato al control judicial.

La lógica del contrato parece ser extraña a la lógica de la articulación del castigo penal. El contrato parece ser una clase de interacción social que se encuentra claramente determinada por la libertad de suscribir acuerdos en pie de igualdad. Es poco claro que esas condiciones generales puedan compartirse en el marco de un proceso penal.

Además, puede considerarse que el mismo control judicial puede ser determinado por una visión de la libertad y la igualdad como la revisada anteriormente. Como hemos señalado, existen interferencias justificadas que pueden verificarse en el ejercicio de la libertad bajo esta de idea de «no-dominación», lo que podría guiar al juez en la revisión de ese escenario de interferencia, sobre todo considerando que el acuerdo se realiza a propósito del ejercicio del plan punitivo estatal.

La idea de igualdad defendida por los republicanos es también útil para el control judicial del acuerdo. Es claro que ese acuerdo debe realizarse en condiciones de igualdad, pero, como se realiza en un contexto de una fuerte interferencia, resulta relevante verificar la protección de los intereses de la parte más débil en el acuerdo. Esto puede realizarse teniendo en consideración una tesis igualitaria exigente como la defendida por los republicanos.

Finalmente, creemos que una revisión de la institución realizada de este modo permite formular un juicio crítico en torno a su alcance. Parece ser recomendable que la idea de contratar con énfasis reparatorio en el proceso penal solo debería estar limitada por la concurrencia de los denominados crimina mala in se, que son conceptualizados como crímenes que se construyen en torno a intuiciones básicas de 
castigo y de falta de indiferencia. En esta medida, la regulación acerca del acuerdo reparatorio, más que definir en qué clase de delitos es posible realizar el acuerdo, debería enfocarse en definir el núcleo duro de los delitos que puedan considerarse mala in se, de manera de racionalizar el uso de la persecución penal en esos determinados casos. De ser así, debe darse lugar a una definición de criterios que permitan excluir al acuerdo de aquellos casos en los que la libertad de contratación deba quedar supeditada a la realización del castigo.

\section{Referencias}

Besson, Samantha y José Luis Martí (2009). «Law and Republicanism: Mapping the Issues». En Samantha Besson y José Luis Martí (editores), Legal Republicanism. National and International Perspectives (pp. 3-36). Oxford: Oxford University Press.

Bovino, Alberto (1998). Problemas de derecho procesal penal contemporáneo. Buenos Aires: Del Puerto.

Braithwaite, John y Philip Pettit (1990). Not Just Desert: A Republican Theory of Criminal Justice. Oxford: Clarendon Press.

Carnelutti, Francesco (1960). Cuestiones sobre el proceso penal. Buenos Aires: El Foro.

Correcher, Jorge (2013). «Evolución del derecho penal en el ámbito internacional. Pluralismo y garantismo jurídico-penal como criterios orientadores». Cuadernos Electrónicos de Filosofía del Derecho, 28: 109-128. Disponible en bit.ly/318MaBG.

Cortina, Adela (1985). «La justificación ética del derecho como tarea prioritaria de la filosofía política: Una discusión desde John Rawls». Doxa, 2: 129-144. Disponible en bit.ly/34ZoJfm.

Costa, Victoria (2009). «Neo-republicanism, freedom as non-domination, and citizen virtue». Politics, Philosophy \& Economics, 8 (4): 401-419. Disponible en bit. ly/35mfTbG.

DAGger, Richard (2008a). «Punishment as fair play». Res Publica, 14: 259-275. Disponible en bit.ly/30cmsGj.

-. (2008b). «Republican Punishment: Consequentialist or Retributivist?». En Cecile Laborde y John Maynor (editores), Republicanism and Political Theory (pp. 219245). Oxford: Blackwell Publishing.

-. (2009). «Republicanism and Crime». En Samantha Besson y José Luis Martí (editores), Legal Republicanism. National and International Perspectives (pp. 147-166). Oxford: University Press.

Delgado, Jordi y Carnevali, Raúl (2020). «El rol del juez penal en los acuerdos reparatorios: soluciones alternativas efectivas». Política Criminal, 15 (29): 1-24. Disponible en bit.ly/2FLlz6m. 
DíAz, Alejandra (2010). «La experiencia de la mediación penal en Chile». Política Criminal, 5 (9): 1-67. Disponible en bit.ly/3odIkBa.

Duff, R.A. y Sandra Marshall (1998). "Criminalization and Sharing Wrongs». Canadian Journal of Legislation and Jurisprudence, 11 (1): 7-22. Disponible en bit. ly/3dKVC3m.

Gargarella, Roberto (1999). Las teorías de la justicia después de Rawls: Un breve manual de filosofía política. Barcelona-Buenos Aires-México: Paidós.

Markell, Patchen (2008). «The Insufficiency of Non-Domination». Political Theory, 36 (1): 9-36. Disponible en bit.ly/34hHDyM.

MARTí, José Luis (2006). La república deliberativa. Una teoría de la democracia. Madrid-Barcelona: Marcial Pons.

-. (2009). «The Republican Democratization of Criminal Law and Justice». En Samantha Besson y José Luis Martí (editores), Legal Republicanism. National and International Perspectives (pp. 123-146). Oxford: University Press.

Moreso, José Juan (2009). «Las virtudes epistémicas de la República deliberativa». Diritto \& Questioni Pubbliche, 9: 315-322. Disponible en bit.ly/3dVFFrr.

Peтtit, Philip (1999). Republicanismo. Una teoría sobre la libertad y el gobierno. Barcelona-Buenos Aires-México: Paidós.

-. (2005). «La libertad republicana y su trascendencia constitucional». En María Julia Bertomeu, Antoni Domènech y Andrés de Francisco (compiladores), Republicanismo y Democracia (pp. 41-68). Buenos Aires: Miño y Dávila.

-. (2006). Una teoría de la libertad. Buenos Aires: Losada

RoselL, Jorge (2009). «Los postulados del garantismo en el proceso penal. Muestra jurisprudencial». Revista de la Maestría en Derecho Procesal, 3 (1). Disponible en bit.ly/2Hkdugl.

SALAS, Minor (2012). «Sin derecho ni razón. Sobre el garantismo penal de L. Ferrajoli: Su carencia de validez científica y de practicidad real». DOXA, Cuadernos de Filosofía del Derecho, 35: 751-789. Disponible en bit.ly/2HmHWzs.

Skinner, Quentin (2010). «On the Slogans of Republican Political Theory». European Journal of Political Theory, 9 (1): 95-102. Disponible en bit.ly/2FRFmkM.

Valenzuela, Jonatan (2017). Hechos, pena y proceso. Santiago: Rubicón.

VAN DER RIJT, Jan-Willem (2009). «Republican Dignity: The Importance of Taking Offence». Law and Philosophy, 28 (5): 465-492. Disponible en bit.ly/37pmEw1.

VIDELA, Lino (2010). «Los acuerdos reparatorios a la luz del concepto de reparación». Revista de Estudios de la Justicia, 13: 293-321. Disponible en bit.ly/37s74jw.

VIroli, Maurizio (2001). «El sentido olvidado del patriotismo republicano». Isegoría, 24: 5-14. Disponible en bit.ly/31scSp5.

WALKER, William (2006). «Sallust and Skinner on Civil Liberty». European Journal of Political Theory, 5 (3): 237-259. Disponible en bit.ly/3jlmRCF. 


\section{Reconocimiento}

Este trabajo se escribió en el marco del proyecto Fondecyt regular 1191634 llamado «Error y proceso judicial».

\section{Sobre el autor}

Jonatan Valenzuela es profesor de Derecho Procesal en la Universidad de Chile y doctor en Derecho por la Universidad de Girona. Su correo electrónico es jvalenzuela@derecho.uchile.cl. (iD https://orcid.org/oooo-0002-9792-5637. 
La Revista de Estudios de la Justicia es publicada, desde 2002, dos veces al año por el Centro de Estudios de la Justicia de la Facultad de Derecho de la Universidad de Chile. Su propósito es contribuir a enriquecer el debate jurídico en el plano teórico y empírico, poniendo a disposición de la comunidad científica el trabajo desarrollado tanto por los académicos de nuestra Facultad como de otras casas de estudio nacionales y extranjeras.

\author{
DIRECTOR \\ Álvaro Castro \\ (acastro@derecho.uchile.cl) \\ SITIO WEB \\ rej.uchile.cl \\ CORREO ELECTRÓNICO \\ cej@derecho.uchile.cl \\ LICENCIA DE ESTE ARTÍCULO \\ Creative Commons Atribución Compartir Igual 4.o Internacional
}

La edición de textos, el diseño editorial y la conversión a formatos electrónicos de este artículo estuvieron a cargo de Tipográfica

(www.tipografica.io) 